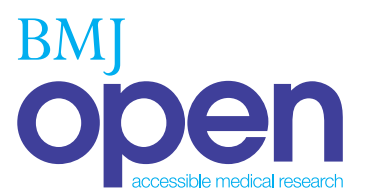

\title{
'Are decisions about discharge of elderly hospital patients mainly about freeing blocked beds?' A qualitative observational study
}

\author{
Anne Wissendorff Ekdahl, ${ }^{1,2}$ Märit Linderholm, ${ }^{3}$ I Hellström, ${ }^{1,2}$ Lars Andersson, ${ }^{4}$ \\ Maria Friedrichsen ${ }^{2,5}$
}

To cite: Ekdahl AW, Linderholm M, Hellström I, et al. 'Are decisions about discharge of elderly hospital patients mainly about freeing blocked beds?' A qualitative observational study. BMJ Open 2012;2:e002027. doi:10.1136/bmjopen-2012002027

- Prepublication history for this paper are available online. To view these files please visit the journal online (http://dx.doi.org/10.1136/ bmjopen-2012-002027).

Received 29 August 2012 Accepted 22 October 2012

This final article is available for use under the terms of the Creative Commons Attribution Non-Commercial 2.0 Licence; see http://bmjopen.bmj.com
For numbered affiliations see end of article.

\section{Correspondence to} Dr Anne Wissendorff Ekdahl; anne.ekdahl@lio.se

\section{ABSTRACT}

Objective: To explore the interactions concerning the frail and elderly patients having to do with discharge from acute hospital wards and their participation in medical decision-making. The views of the patients and the medical staff were both investigated.

Design: A qualitative observational and interview study using the grounded theory.

Setting and participants: The setting was three hospitals in rural and urban areas of two counties in Sweden of which one was a teaching hospital. The data comprised observations, healthcare staff interviews and patient interviews. The selected patients were all about to be informed that they were going to be discharged.

Results: The patients were seldom invited to participate in the decision-making regarding discharge. Generally, most communications regarding discharge were between the doctor and the nurse, after which the patient was simply informed about the decision. It was observed that the discharge information was often given in an indirect way as if other, albeit absent, people were responsible for the decision. Interviews with the healthcare staff revealed their preoccupation with the need to free up beds: 'thinking about discharge planning all the time' was the core category. This focus not only failed to fulfil the complex needs of elderly patients, it also generated feelings of frustration and guilt in the staff, and made the patients feel unwelcome.

Conclusions: Frail elderly patients often did not participate in the medical decision-making regarding their discharge from hospital. The staff was highly focused on patients getting rapidly discharged, which made it difficult to fulfil the complex needs of these patients.

\section{INTRODUCTION}

Healthcare professionals have a responsibility to involve patients in decisions concerning their care and treatment. This has been accepted as an ethically appropriate practise and is a part of healthcare legislation in many

\section{ARTICLE SUMMARY}

Article focus

- The participation of frail elderly patients in the medical decision-making regarding their discharge from acute hospitals.

\section{Key messages}

- Doctors and nurses often excluded elderly patients from discussions about their discharge, and the patients often felt they had a very little opportunity to participate in the decision-making process.

- The healthcare staff focused on the quick turnover of beds, which led to frail elderly patients feeling unwelcome in the hospital and made the healthcare staff feel frustrated and guilty.

- Even though frail elderly patients form a common group in hospitals, hospital care is not adapted to their complex needs. More age-attuned hospital care is needed.

Strengths and limitations of this study

- The study addressed an important issue in future healthcare, which has been poorly studied to date.

- Several methods of data collection.

- The qualitative methods limit the generalisation of the results.

countries. ${ }^{1-3}$ In addition, patient participation in decision-making is associated with higher patient satisfaction and improved treatment outcomes, ${ }^{1} 45$ which shows that adequate patient participation is important for both patients and policy makers. However, a systematic review has shown that patients generally want to participate more than they do at present. ${ }^{6}$ This also applies to elderly patients, ${ }^{7}$ although the preferences are highly individual with a range from a very passive to very active in the medical decision-making. ${ }^{8-10}$

The coming half of the century will see an increase in the elderly population due to "the 
greying of the baby boomers'. ${ }^{11}$ Increasing survival to an older aged person means that the prevalence and coexistence of age-related diseases are increasing. However, a factor that complicates the care of frail elderly patients who have multiple needs is the traditional focus of hospital wards on only one or a few medical conditions; ${ }^{12} 13$ and a lack of access to multidisciplinary teams that can meet the complex needs of frail elderly patients. This means that, although frail elderly patients and geriatric syndromes are common in hospitals, ${ }^{12-14}$ the hospitals do not focus on taking care of them and they are sometimes perceived as not fitting in by the healthcare staff. ${ }^{15}$

Earlier studies on the participation of elderly patients in decision-making in hospital wards have led to a deeper understanding of participation and what it means to these patients. ${ }^{16} 17$ In general, the patients did not expect to be involved so much in decision-making. Submission to and trust in the healthcare were often expressed. A recent study from Norway, based on interviews during the first 2 weeks after discharge, revealed that elderly patients have a clear preference for participation and they did not feel that they were involved in discussions regarding their discharge. ${ }^{18}$

An important opportunity for a patient to be involved in medical decision-making regarding discharge planning is the ward round, although the encounter between the patient and doctor is often very short. ${ }^{19}$ However, research into communication between patients and physicians during the ward round is limited, and seems to be focused on education rather than medical decision-making. ${ }^{20-22}$

Our earlier studies ${ }^{7} 1523$ were based on data from interviews with patients after discharge, patient questionnaires and focus group interviews with doctors which give one type of data. We now wanted to study the interactions of patient participation while in progress by making observations of the decision-making process.

\section{AIMS}

To explore the interactions concerning the frail and elderly patients having to do with discharge from acute hospital wards and their participation in medical decision-making. The views of the patients and the medical staff were both investigated.

\section{METHODS}

This was a qualitative study that consisted of observations, interviews with patients who were still in hospital and interviews with the doctors and nurses using a Grounded Theory approach.

\section{Setting and participants}

The setting comprised two internal medicine wards, one general surgery ward and one acute care ward. All had many elderly patients. The hospitals consisted of one teaching hospital and two general hospitals in rural and urban areas of Sweden, each of which served a population between 120000 and 170000 inhabitants (table 1)

\begin{tabular}{ll} 
Table 1 Description of data \\
\hline Hospitals & Teaching hospital $(n=1)$ \\
& General hospitals $(n=2)$ \\
Type of wards & Internal medical wards $(n=2)$ \\
& Emergency ward $(n=1)$ \\
& General surgical ward $(n=1)$ \\
Days of observation & Internal medical wards $(n=11)$ \\
& Emergency ward $(n=5)$ \\
Number of interviews & General surgery ward $(n=10)$ \\
& Patients $(n=9)$ \\
& Doctors $(n=3)$ \\
& Nurses $(n=6)$ \\
\hline
\end{tabular}

For description of the interviewed patients please see table 2.

The doctors' ward rounds began with a meeting with the chief physician, the junior doctors and the nurses (often 5 or 10 persons in total). In these meetings, all patients were discussed, mostly on the basis of a data screen based on the patients' medical records and reports from the nurses. Thereafter, the ward rounds started. This process was observed and analysed over a period of approximately $180 \mathrm{~h}$.

\section{Data collection}

Participant observation has been described as a method by which the researcher engages in a "process of learning through exposure to, or involvement with, the day-to-day routine activities of participants in the research setting. ${ }^{24-26}$ The researcher's degree of involvement with participants may vary from being situated on the periphery as an observer to being actively engaged with the participants in their daily activities. ${ }^{27}$ In the present study, the observers were mostly situated in the periphery, where they sought to avoid disturbing the decision-making process and participant interactions. Before the first observation period on each ward, the observers had a short meeting with the doctors and nurses to explain the aims of the study, that all participation was voluntary, and that the study had an ethical approval (Dnr 2011/371-31). The observers also

Table 2 Age and gender of the interviewed patients and their preferred and actual roles in medical decision-making

\begin{tabular}{lll}
\hline Patient & Age (mean 85.7 years) & Gender \\
\hline $\mathrm{A}$ & 90 & $\mathrm{f}$ \\
$\mathrm{B}$ & 90 & $\mathrm{f}$ \\
$\mathrm{C}$ & 88 & $\mathrm{~m}$ \\
$\mathrm{D}$ & 82 & $\mathrm{~m}$ \\
$\mathrm{E}$ & 90 & $\mathrm{~m}$ \\
$\mathrm{~F}$ & 84 & $\mathrm{~m}$ \\
$\mathrm{G}$ & 79 & $\mathrm{~m}$ \\
$\mathrm{H}$ & 87 & $\mathrm{f}$ \\
$\mathrm{J}$ & 76 & $\mathrm{~m}$ \\
M & 91 & $\mathrm{f}$ \\
\hline
\end{tabular}


informed the medical staff that they would need their help to identify patients to interview, and that they wanted to interview some of the nurses and doctors who were working during the days of observation. The staff was specifically asked to identify those patients who were over 75 years of age, preferably with complex diseases and on their way home; they were requested to ask the patients whether they would participate in an interview. If the patient agreed, the observer would then give the patient more information about the study, reassure the patient that all participation was voluntary, and ask for a written informed consent.

Despite the stress of the hospital environment, the staff had a very friendly attitude towards the observers and was open to discussing problems and giving time for interviews.

The observers were present during both the sitting and walking rounds. The patients who were interviewed later were identified during the morning reports and the rounds. Short notes were made during the observations. Immediately after each observational period, the notes were transcribed in more detail onto a computer. All of the interviews with the nine patients and the nine healthcare staff (three doctors and six nurses) lasted between 10 and $30 \mathrm{~min}$; interviews were tape-recorded and transcribed verbatim. The observations were made by the first and second authors (AE and ML, respectively). The data-collection period was between October 2011 and March 2012.

The preunderstanding of the observers is as follows: first author (AE) is a geriatrician with more than 20 years of experience in geriatric medicine and is used to doing medical rounds and discussing medical decisions with patients and relatives. The second author (ML) is a district nurse with a similar length of experience in primary care. The fifth author (MF) is a senior lecturer with experience in research and nursing in internal medicine and palliative care.

\section{Data analysis}

The observations and interviews were interpreted by using the grounded theory, a so-called constant comparative method. ${ }^{28} 29$ The grounded theory methodology can be used in participant observation methods to explore under-researched areas. $^{27}$ The use of the grounded theory method meant that analysis started as soon as data collection started. Thus, the first step involved an initial coding process whereby certain text sequences were given substantive code names. Thereafter, the substantive codes were interpreted further to explain larger segments of the data; ${ }^{28}{ }^{29}$ this resulted in the development of preliminary categories. At the same time, constant comparisons between and within the preliminary categories were made to see if the categories were well described and to make rearrangements if needed for a better understanding of the processes in the data material. ${ }^{28}{ }^{29}$ Thus, data collection and data analysis were performed simultaneously to guide further data collection, and questions were asked repeatedly to improve the definition of the categories; this continued until no new categories emerged and no new properties within the categories were identified. Integrative diagrams and memos were written throughout the process to guide thinking and the three observers and authors (AE, ML and MF) had several meetings to discuss their analytical insights and interpretations.

The Control Preference Scale results are presented using descriptive statistics.

\section{Rigour}

Triangulation $^{28}{ }^{30}$ was applied through several data collection methods-observations, field notes and the interviews. Regular meetings were held by three of the authors (ML, MF and AE) to review the evolving understanding and to discuss further sampling. Initially, two researchers ( $\mathrm{MF}$ and $\mathrm{AE}$ ) performed the coding independently, with similar results. The different nature of the wards in which observations were made increased the variation between categories.

\section{Findings}

During the analytical process, four categories were defined. Figure 1 shows an overall integrative diagram that describes these categories. The first category described the reasons used by doctors and nurses to discharge patients; the second category was the discussion between the doctors and nurses regarding the decision to discharge the patient before meeting the patient; the third category was the communication between the patient and the doctors/nurses regarding the decision of the latter to discharge the patient; and the fourth category described the reactions from the patients and staff regarding decisions of discharge.

The core category detected was 'Thinking about discharge all the time'.

\section{The reasons used by doctors and nurses to discharge a patient}

The pace of work on the wards was often high, with patients coming and leaving rapidly. All staff had adapted to this pace and many felt that one of their most important duties was to discharge patients because they needed beds for other incoming patients. This overriding preoccupation was always 'hanging in the air'. A nurse in one ward said:

\footnotetext{
There is a very high inflow of patients all the time-so you have to discharge patients to make beds available. As soon as you feel care can be given out of hospital, you must facilitate it.
}

Most doctors and nurses felt they were doing the right thing when they achieved a fast turnover, but they also said that there was always the risk that the patients would have to return the next day. In some wards, nurses did not know whether a patient should be discharged or not 


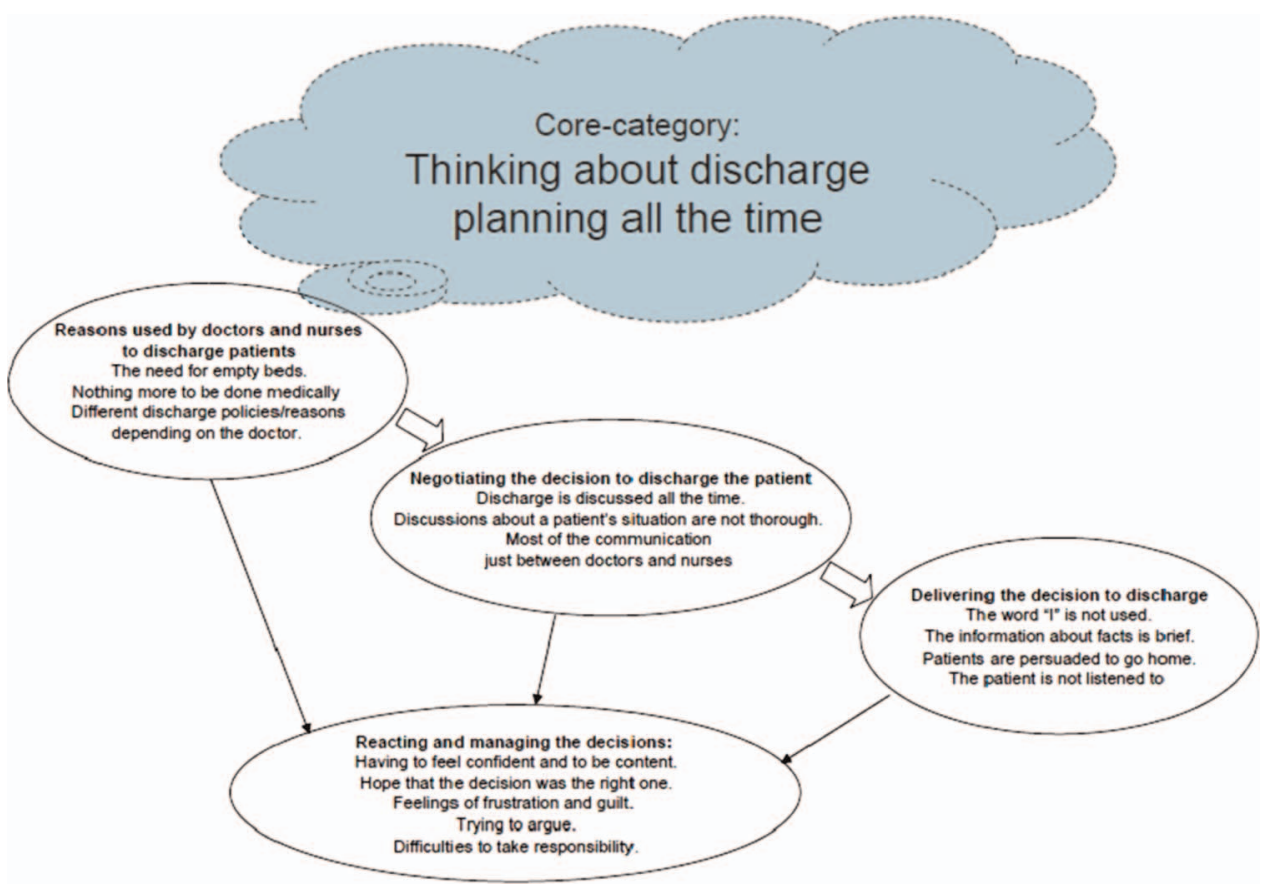

Figure 1 Overall integrative diagram of the main categories determined by the study.

because that decision was dependent on the doctor in charge. Some doctors were described as 'warm-hearted and kind' and would allow the patients to stay for a day or two longer so that social support could be arranged. Other doctors were described as 'cold' or 'harder' and would discharge patients promptly when 'there was no more to be done medically' meaning that there was no need for them to stay in hospital and occupy a hospital bed despite having severe symptoms. The following observation relates to a discussion in a sitting round about a woman who was born in 1926, who had chronic obstructive lung disease (COPD) for many years and who was now in the ward due to difficulty in breathing and anxiety:

Nurse: 'She could probably go home? We are not doing anything special with her; she does not want more help (from the municipality) and has the same medicine as before.'

Doctor: 'Then we just say "Goodbye” to her'

The patients also had difficulty in adapting to the fast pace on the wards and found it hard to accept the reason for being discharged. Many of them said that they needed to, and wanted to, stay longer in hospital than they were allowed to:

I think it's totally wrong to send me home. I've been here for two days and now I'm going home again. But I'm not better than I was when I came here.
They wanted to feel better before returning home because they were tired and felt that they had not recovered sufficiently. Some said that the reason they wanted to stay in the hospital was that they were anxious and lonely.

\section{Negotiating the decision to discharge the patient}

The need to discharge patients was constantly on the minds of all staff. Consequently, when the nurses met early in the morning so that they could plan their work for that day, the focus was on finding candidates for discharge, especially if the ward had few beds available or if a patient had been on the ward for 'too long'. This discussion continued in the sitting rounds and was initiated by either the doctors or the nurses. This discussion did not always involve a thorough review of the patient's situation; rather it mainly revolved around the reports or opinions of the nurses, the basic functions of the patients, and a review of the previous assessments and tests in the patient records. The following observation illustrates how fast and brief these communications regarding patient discharge mostly were: it relates a discussion during a sitting round between a doctor and a nurse on the ward regarding an 84-year-old male patient:

Doctor: 'How is he today?'

Nurse: 'He's a little tired man'. 
Doctor: 'Has he been eating and drinking? We will go and watch and talk to him. $\mathrm{He}$ is a candidate for discharge'

In a few cases, the discharge decisions were discussed more deeply. The following example is of a nurse who tried to convince the senior consultant that the patient was too ill for discharge. The patient was an old man with diarrhoea who would not accept home help from the municipality with home help services:

Nurse: 'How will it work for them back home?'

Senior consultant: 'This is not really our problem. They want to take care of themselves. Maybe his wife is healthy and eager? He'll probably have it better home than in hospital.'

Junior doctor: 'But if you think as a human being?'

Consultant: 'It's their business if they don't want more help.'

Senior nurses told more junior nurses not to feel too responsible and not to dwell too deeply on what would happen when the frail elderly patients got home again.

\section{Delivering the decision to discharge the patient}

Depending upon the patient's age and health status, the decision to discharge him or her was expressed in different ways. Middle-aged patients were given more concrete information regarding investigations, tests and treatments, whereas the information given to the elderly was scantier. On the walking rounds, the doctors and nurses seemed to follow the decisions made during the sitting rounds regardless of what the patient said. Most doctors used body language, specific words and leading or persuasive questions that implied that patients 'should' now feel better, and then focused directly on the discharge of the patient. The following observation is from a walking round in which a 90-year-old woman met the doctor in charge:

Doctor: 'Feel better now? Do you feel like you should be able to come home today?'

Patient: 'I don't know. I find it hard to decide if I'm feeling better today. I'm still dizzy.'

Neither the doctor nor the nurses seemed to take notice of her answer.

Doctor: 'Don't you feel better after the blood that was given yesterday? Your blood values are better; one could think that you should go home today. Consider the matter.'

The doctor then backed out of the room, his body language suggesting that he was ready to go that this discussion was finished.

Patient: 'Well, thank you so much.'
Sometimes patients were asked to think about the doctor's suggestion, but most often it was taken for granted that the patient would go home the same day. In addition, when the doctors and nurses met elderly patients on the walking round, although they listened politely to them, they made few or no comments. Instead, after the patient had spoken, they refocused on the planned discharge and when the patient would be going home (for instance after lunch).

Doctors also used specific words when talking to patients about the decision to discharge. They suggested that not only they themselves, but also other, albeit absent, people were responsible for the decision to discharge even though the decision to discharge had been made just a few minutes earlier by the doctor himself/ herself. They did this by using words such as 'we' or 'one', instead of 'I'. For example, 'we think that it might be possible to continue treatment at home'. Occasionally, they used more non-specific sentences such as 'It could be imagined that it will be good to come home today'. This type of formulation was used in general in all departments. When it was mentioned to the doctors during interviews, they expressed surprise, but also acceptance, that they actually did formulate their decisions in this way.

Some nurses also admitted that they frequently persuaded patients to go home. This is exemplified by the following comment by a nurse:

One can always try and really talk about the problem and say: 'We cannot do anything more for you here and this is unfortunately an acute care hospital and there are others who need this bed more.'

Not all doctors behaved as described above. Some sat down with their patients and, irrespective of the patient's age and health status, focused on the patient and listened respectfully.

\section{Reacting and managing decisions}

The frail elderly patients with multiple morbidities on the wards were often in a rather poor condition and very tired. This meant that they could not express themselves well, which hampered their ability to participate in the medical decision-making. All patients hoped that doctors and nurses had made the right decision in discharging them, even if they were not convinced. Therefore, they submitted to the decision to be discharged and tried to feel satisfied about it. This attitude is exemplified by the following quote from a 90-year-old woman:

Interviewer: 'Could you imagine how you would like it to be when decisions are made about your care? How would you like it to be?'

Patient: 'I don't think you can influence decisions and that it's just as well because you don't know. I don't 
understand the care that much. So it is enough just to hope they take the right decision.'

Interviewer: Do you think so?

Patient: Yes. I can't influence them.

In general, patients seemed to feel that when they came to the hospital with their illnesses, they did not have the knowledge to question decisions about their medical care. Most patients agreed with the decision, others felt they had no other choice but to agree and others disagreed, some openly. An example of the latter was a woman, born in 1922, who argued for about five minutes with the doctors and nurses on the walking round. She said that she needed help with her diabetes, COPD, rectal cancer, and urinary incontinence. However, she did not succeed in altering their decision of discharging her. She said:

I called my son at work and he thinks this is hard. But they want to get rid of me, that's the way it is.

This woman's behaviour confused the doctors and made them feel dejected. After leaving her, they started discussing how they should persuade her to go home.

Other patients felt uncomfortable because of the way the staff behaved with them during the meeting to discuss their discharge. Some said that they felt that the staff had just informed them, and they had not been asked for their opinions or their participation. They felt they were not treated as equal:

Patient: 'Suddenly when you get over 70-whatever responsible work you have had before-you are suddenly an idiot. It is like the nurses don't have any grandparents or know older people themselves-they are talking to us just like to children'.

Some of the staff expressed feelings of frustration and guilt about the rapid discharge of frail elderly patients: they often felt uncertain about how the patients would cope once they got home and did not always feel that they were doing a good job despite fulfilling the goal of rapid a turn-over.

Nurse: 'Sometimes it feels as if my heart is bleeding when I have to say that this care can be given at home. You kind of want to get rid of them, because we can do no more and they cannot stay. So then you feel so frustrated and helpless.'

Nurse: 'I'm quite unsure how it really will work back home. I can see the headlines in the papers: "Nurse sent home an elderly, severely ill patient too early"!

The last quotation giving an expression by the nurse that it is difficult to take responsibility of the care given to frail elderly patients'.

\section{Core category}

The core category that could explain the findings in this study was 'thinking of discharge all the time'. This core category opposes the mandate of the medical staff to focus on fulfilling the needs of patients at hand. It explains why the pace on the wards was so fast, why elderly patients were not invited to participate in medical decision-making process, why the staff did not always feel happy about the decisions they made, and why the patients did not feel welcome in the hospital.

\section{DISCUSSION}

The results showed that elderly with multiple morbidities have difficulties in participating in medical decisionmaking when in hospital. Most of the discussions that led to the decision to discharge a patient were between nurses and doctors; the patient was rarely involved. The patients were often content with the information they received and did not expect to participate actively. These findings are consistent with those of other studies in this patient group. ${ }^{16} 2331$ Qualitative studies about the participation of older patients in decision-making regarding their discharge also found that the patients did not really expect to participate, and tended to be resigned to submitting to circumstances. One study also showed that the rigid hospital routines such as time schedules and impersonal manner of assessments had a negative impact on patient participation. ${ }^{17}{ }^{32}$ Notably, the latter study was an action research study in which the main action was to encourage the staff to promote patient participation. ${ }^{17}$ The conclusion of that study was that it is possible to improve participation (in that case, by reflecting on the daily interactions of the staff with the patients).

It is possible that the patients in the present study said that they were satisfied with not having a choice because they felt that they could not influence the discharge decision anyway. An example is in the quotation when the patient says 'thank you' to a decision she obviously did not agree to. This is illustrating how the patients often express gratitude and subordination to decisions they do not agree to, and it shows the perceived superior position of the healthcare. This caused them to adopt a pragmatic attitude, where they were content and simply hoped that the right decisions were being taken. They also said that one of the reasons they did not want to participate was because they lacked medical knowledge. A low health literacy makes it difficult for patients to participate, which increases the risk of poor health outcomes. $^{33} 34$ This problem is heightened in elderly patients because they often have very complex health conditions and are at an increased risk of a cognitive decline.

The body language of the doctor, the speed with which the doctor communicated with the patient, and the content of the communication did not invite the patients to participate. Significantly, when the patients 
were informed about the decision of his/her discharge, the language that was used was often indirect and suggested that someone other than the doctors and nurses present had made the decision to discharge. It seemed as if they were not taking responsibility for their own decisions, that they were indicating that they did not really approve of the decisions and that the responsibility lay with someone else. To our knowledge, this way of communicating with patients has not been documented previously.

The problems of elderly patients are often complex because they have social and rehabilitation needs as well as requiring care for their various medical conditions. This means that these patients cannot be treated hastily. The core category 'thinking of discharge all the time' showed that the staff perceived that one of their main tasks was to make beds available. This led them to not risk inviting these complex and time-consuming patients to participate in decision-making, as they knew that many of these patients wanted to postpone their discharge. The staff expressed feelings of moral distress such as frustration and guilt. These feelings may have contributed to the impression of the elderly patients that they were not welcome in hospital. In fact, this may even have been one of the reasons why the patients felt uncomfortable and thought that the staff wanted to get 'rid of them'.

It is natural that doctors have the responsibility to decide on the basis of their knowledge when patients are well enough to go home, and they cannot allow the patient too much leeway in this decision because that would result in 'bed-blocking'. In Sweden, like in many other countries, hospitals are mainly funded by the income tax and it is in the interest of all in society including the doctors that patients do not unnecessarily occupy expensive hospital beds. Nevertheless, it is an important finding that there was very little communication with the elderly patients. One notable observation was that the speed of discharge seemed to depend upon the doctor in charge and his/her attitude to frail elderly people. This suggests that, from a medical point of view, little is known about the optimal time needed to discharge frail elderly patients and as a result, the focus lies on the availability of beds.

The present study gives us an indication that probably younger and older patients are not treated equally: the doctors and nurses communicated less with the older patients than with younger patients. The elderly patients who were interviewed also said they felt unwelcome in hospital. This discrimination experienced is not in line with the laws in Sweden. ${ }^{35}$

\section{DISCUSSION OF THE METHODS USED IN THE PRESENT STUDY}

Observational methods, when used with qualitative methodologies, are useful when little is known about a topic and/or a complex phenomenon needed to be understood. ${ }^{36}$ A qualitative observational study can help identify discrepancies between what people do and what they say, and the grounded theory is suitable for analysing the observations generated by such studies. ${ }^{29} 37$ One of the problems with observational studies is that it is impossible to record everything and the results depend on the observers, who serve as research instruments that select what to write down in field notes and full observations. It is unclear whether our presence as observers influenced the care that was given by the staff, which was aware that our focus was on patient participation. However, given the results of the study, it seems that patient participation would probably not have been better if we had not been present. Therefore, our presence as observers probably did not influence the results to be more positive than those observed.

The hospital wards that were studied were chosen because they had many elderly patients. To yield a wider picture, wards from both general and teaching hospitals located in two different counties and those that had different medical specialities were selected.

\section{CONCLUSIONS}

The present study showed that elderly patients did not participate much in medical decision-making regarding their discharge. This has also been shown by earlier studies. ${ }^{7} 171823$ The language that was used while delivering the decision of discharge was often indirect and the words 'I have decided' were seldom used, making it difficult for the patient to know whom to question in case of disagreement. Frail elderly patients require hospital care from time-to-time and these patients have been increasing in number. It is, therefore, important that hospital care is adapted so that elderly patients are provided with a good and and dignified care. It would probably be better if these patients are cared for in age-attuned hospital wards (when hospital care is needed) rather than the super-specialised and diagnosis-oriented hospital wards that are particularly common these days. ${ }^{13}$

\section{Author affiliations}

${ }^{1}$ Department of Geriatric Medicine, Vrinnevi Hospital, Norrköping, Sweden ${ }^{2}$ Department of Social and Welfare Studies, Faculty of Health Sciences, Linköping University, Norrköping, Sweden

${ }^{3}$ Valdemarsviks Primary Care Center, County Council of Östergötland, Valdemarsvik, Sweden

${ }^{4}$ National Institute for the Study of Ageing and Later Life (NISAL), Linköping University, Norrköping, Sweden

${ }^{5}$ Palliative Education and Research Center, Vrinnevi Hospital, Norrköping, Sweden

Contributors $A E$ drafted the manuscript, $A E, M L$ and MF participated in the design of the study. AE and MF performed the qualitative analysis. All authors read and approved the final manuscript, which was then reviewed by an English language editor.

Funding This work was supported by the County Council of Eastern Östergötland, which financed the salary costs of $A E$ and MF for this study. The Swedish government supplied additional financial support through funding for medical training and research.

Competing interests None. 
Ethics approval The researchers were not in any way connected to the medical care of the patients. Ethical considerations were observed according to the recommendations of the Helsinki declaration as suggested by Wilkie. ${ }^{38}$ The Ethical Review Board of Linköping University approved the study (Dnr 2011/337-31)

Provenance and peer review Not commissioned; externally peer reviewed

Data sharing statement Extra data (interviews in full-text and memos of the observations) are available. Please email anne.ekdahl@lio.se

\section{REFERENCES}

1. Frosch DL, Kaplan RM. Shared decision making in clinical medicine: past research and future directions. Am J Prevent Med 1999:17:285-94.

2. Health care legislation in Sweden (1982:763) 1982-06-30, Omtryck: SFS 1992:567 Uppdaterad: t.o.m. SFS 2007:403 ed: Rixlex, 1982

3. World Heath Organization. A declaration on the promotion of patients' rights in Europe. Amsterdam: WHO, 1994.

4. Greenfield S, Kaplan S, Ware JE. Expanding patient involvement in care. Effects on patient outcomes. Ann Intern Med 1985;4:520-8.

5. Maly RC, Bourque LB, Engelhardt RF. A randomized controlled trial of facilitating information given to patients with chronic medical conditions: effects on outcomes of care. J Fam Pract 1999;48:356-63.

6. Tariman JD, Berry DL, Cochrane B, et al. Preferred and actua participation roles during health care decision making in persons with cancer: a systematic review. Ann Oncol 2010;21:1145-51.

7. Ekdahl A, Andersson L, Wirehn A-B, et al. Are elderly people with co-morbidities involved adequately in medical decision making when hospitalised? A cross-sectional survey. BMC Geriatr 2011;11:46.

8. Bastiaens H, Van Royen P, Pavlic DR, et al. Older people's preferences for involvement in their own care: a qualitative study in primary health care in 11 European countries. Patient Educ Counsel 2007;68:33-42.

9. Benbassat J, Pilpel D, Tidhar M. Patients' preferences for participation in clinical decision making: a review of published surveys. Behav Med 1998;24:81-8.

10. Elkin EB, Kim SHM, Casper ES, et al. Desire for information and involvement in treatment decisions: elderly cancer patients' preferences and their physicians' perceptions. J Clin Oncol 2007;25:5275-80.

11. The Europeian Commison: Eurostat: Population projections. 2011. http://epp.eurostat.ec.europa.eu/statistics explained/index.php/ Population_projections (accessed 15 Aug 2012).

12. Labella AM, Merel SE, Phelan EA. Ten ways to improve the care of elderly patients in the hospital. J Hosp Med 2008;6:351-7.

13. Lafont C, Gérard S, Voisin T, et al. Reducing 'iatrogenic disability' in the hospitalized frail elderly. J Nutr Health Aging 2008;15:645-60.

14. McCusker J, Cole M, Abrahamowicz M, et al. Delirium predicts 12-month mortality. Arch Intern Med 2002;162:457-63.

15. Ekdahl AW, Hellström I, Andersson L, et al. Too complex and time-consuming to fit in! Physicians' experiences of elderly patients and their participation in medical decision making: a grounded theory study. BMJ Open 2012;2.

16. Tutton EMM. Patient participation on a ward for frail older people. J Adv Nurs 2005;50:143-52.

17. Huby G, Brook JH, Thompson A, et al. Capturing the concealed: interprofessional practice and older patients' participation in decision-making about discharge after acute hospitalization. $J$ Interprofess Care 2007;21:55-67.

18. Foss C, Hofoss D. Elderly persons' experiences of participation in hospital discharge process. Patient Educ Counsel 2010;85:68-73.

19. Weber H, Stöckli M, Nöbling $M$, et al. Communication during ward rounds in internal medicine: an analysis of patient-nurse -physician interactions using RIAS. Patient Educ Counsel 2007;67:343-8.

20. Jaye $\mathrm{C}$, Egan T, Smith-Han K, et al. Teaching and learning in the hospital ward. N Z Med J 2009;122:13-22.

21. Rowe M, Frantz J, Bozalek V. The role of blended learning in the clinical education of healthcare students: a systematic review. Med Teacher 2012;34:e216-21.

22. Shield ReR, Tong I, Tomas M, et al. Teaching communication and compassionate care skills: an innovative curriculum for pre-clerkship medical students. Med Teacher 33:e408-16.

23. Ekdahl AW, Andersson L, Friedrichsen M. 'They do what they think is the best for me.' Frail elderly patients' preferences for participation in their care during hospitalization. Patient Educ Counsel 2010;80:233-40.

24. Adler PA, Adler P. Observational techniques. Handbook of qualitative research. Thousand Oaks, CA: Sage, 1994, p. 40

25. Angrosino MV. Participant observation and research on intellectual disabilities. The International Handbook of Applied Research in Intellectual Disabilities, New York, NY: John Wiley \& Sons Ltd, 2008:161-77.

26. Hubert J, Hollins S. Men with severe learning disabilities and challenging behaviour in long-stay hospital care. Br J Psychiat 2006;188:70-4

27. Johnson $\mathrm{H}$, Douglas J, Bigby $\mathrm{C}$, et al. The challenges and benefits of using participant observation to understand the social interaction of adults with intellectual disabilities. Augment Alternat Commun 2011;27:267-78.

28. Charmaz K. Constructing grounded theory-a practical guide through qualitative analysis. London: Sage, 2006.

29. Corbin J, Strauss A. Basics of qualitative research. 3rd edn Thousand Oaks, CA: Sage, 2008.

30. Forman J, Creswell JW, Damschroder L, et al. Qualitative research methods: key features and insights gained from use in infection prevention research. Am J Infect Control 2008;36:764-71.

31. Jewell S. Elderly patients' participation in discharge decision making 1. Br J Nurs 1996;5:914-16; 929-32.

32. Huber DL, McClelland E. Patient preferences and discharge planning transitions. J Profess Nursing 2003;19:204-10.

33. Visscher KL, Hutnik CML. Health literacy in Canada and the ophthalmology patient. Can J Ophthalmol/J Can d'Ophtalmol 2012;47:72-8

34. Wolf M, Gazmararian J, Baker D. Health literacy and functional health status among older adults. Arch Intern Med 2005;165:1946-52.

35. The Swedish Government: Law of discremination. 2009. http://www. regeringen.se/sb/d/11043/a/111986?setEnableCookies=true (accessed 15 Aug 2012).

36. Creswell JW. Qualitative inquiry and research design: Choosing among five traditions. Thousand Oaks, CA: Sage, 1998.

37. Polit D, Beck C. Nursing research-appraising evidence for nursing practice. 7th edn. Philadelphia: Wolters Kluwer Health/Lippincott Williams \& Wilkins, 2010.

38. Wilkie $P$. Ethical issues in qualitative research in palliative care. Palliat Med 1997;11:321-4. 